\title{
Laryngeal laceration after blunt neck trauma in a football player
}

\author{
Mariusz P. Łochowski, Marek Rębowski, Józef Kozak, Katarzyna Kozak \\ Regional Multidisciplinary Center of Oncology and Traumatology, Lodz, Poland
}

Kardiochirugia i Torakochirugia Polska 2018; 15 (1): 57-58

Damage of the larynx in athletes is rare. Football players and hockey players constitute the most common group of athletes prone to injuries of this area [1, 2]. It is estimated that the frequency of laryngeal injuries after a blunt trauma of the neck is less than $2 \%$ of all injuries in this area. In the analyzed literature, the authors found only 11 such cases, and the last one was described in 2003 [3]. Because of the rarity of this type of injury, we want to discuss our own experience in dealing with a football player with a laryngeal injury after a blunt neck trauma.

A boy, 17 years old (goalkeeper), suffered a blunt neck trauma as a result of a kick during a football game. Immediately after the injury the patient had rapidly increasing dyspnoea, with enlarged neck circumference and hoarseness. First aid at the stadium was given by the team coach. The ambulance was called. Due to the increasing dyspnea, the emergency doctor intubated the patient and transported him to a surgical ward in the nearest hospital. Due to the bilateral pneumothorax, drainage of both pleural cavities was performed. One hour after the injury the patient was transported to the Department of Thoracic Surgery. In the department the physical examination revealed the presence of subcutaneous emphysema of the neck and chest and compression pain in the place of the injury radiating to the chest. Sonographically there was detected bilateral weakening of the respiratory murmur. In the computed tomography (CT) examination of the chest bilateral pneumothorax and mediastinal emphysema were revealed (Fig. 1). Despite the actively used drainage, reduction of the subcutaneous emphysema was not achieved; on the contrary, it increased. Bronchoscopy was performed, revealing damage to the larynx on the border of the thyroid cartilage and cricoid cartilage. During the $18^{\text {th }}$ hour after the injury cervicotomy was performed. Damage of the cricoid cartilage and thyroid cartilage was detected. The damage had a length of $5 \mathrm{~cm}$. The location of the damage was treated with a single PDS 3-0 suture. Below the place of the damage tracheotomy was performed. The wound was drained with a Redon drain. In the postoperative progress there were no compli- cations. On the $6^{\text {th }}$ day there was performed bronchoscopy, revealing proper healing of the damaged spot without the presence of granulation tissue. The patient was transferred to the Laryngological Clinic for rehabilitation.

Football is one of the most popular sports in the world. From research conducted in Europe it is estimated that approximately $50 \%$ of all sports injuries occur in football. Head injuries in football players appear in 4-22\% cases, while neck injuries are less common (less than 1\%). Multiple minor neck injuries (abrasion, laceration) are asymptomatic, or the symptoms are so small that the damage is not even recognized. In the USA based on research conducted in the Emergency Department (ED) it was found that during 10 years 19000 football players with neck injuries were tested. Only 214 had damage requiring followup. In comparison with athletes of American Football, neck

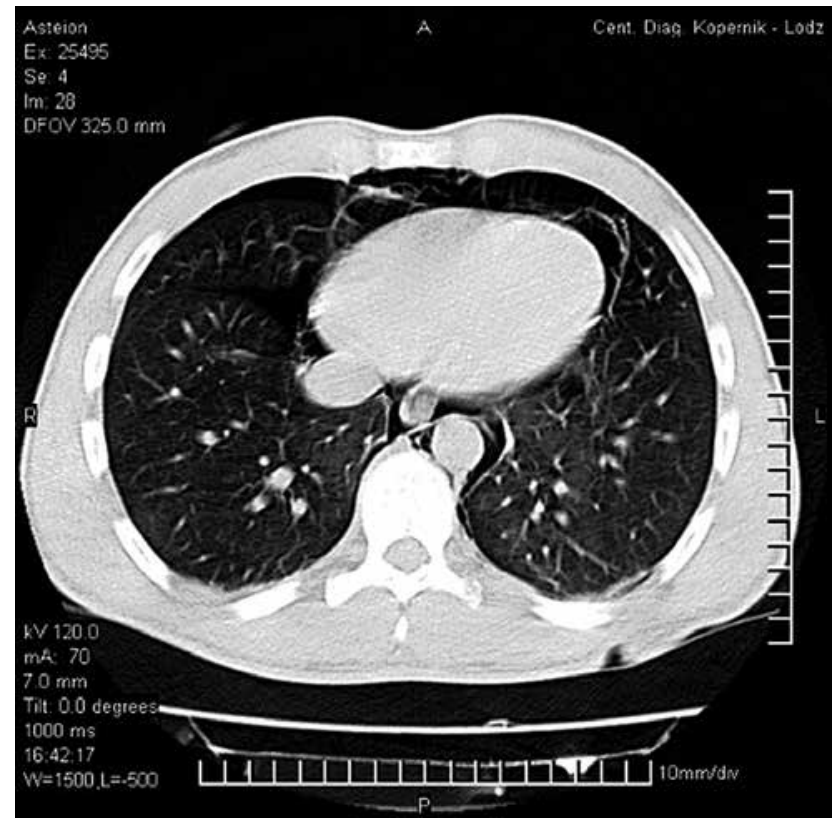

Fig. 1. Computed tomography of chest - bilateral pneumothorax and pneumomediastinum

Address for correspondence: Mariusz P. Łochowski MD, Department of Thoracic Surgery, Memorial Copernicus Hospital, Medical University of Lodz, 62 Pabianicka St, 95-050 Lodz, Poland, phone: +48 602776 887, e-mail: marilo@op.pl

Received: 23.03.2017, accepted: 27.05.2017. 
Table I. Symptoms of laryngeal laceration - interview and physical examination

\begin{tabular}{ll} 
Medical history & Physical examination \\
Voice change & \\
Pain when coughing & Redness of the neck \\
Dyspnoea & Subcutaneous emphysema \\
Stridor & Absence of Adam's apple \\
Shortness and unequal breath & Local tenderness \\
Hemoptysis & \\
Spastic cough & \\
\hline
\end{tabular}

injuries occurs 5 times more often (115 000 cases/10 years), while severe damage of the neck occurs seven times more often [4]. Although damage of the larynx as a result of a blunt injury is rare and the symptoms discrete, in some cases acute symptoms of respiratory insufficiency may occur. In our patient this is exactly the course of disease we observed. Table I presents the most common symptoms of laryngeal damage [2].

The symptoms presented in the table may occur at different frequencies and intensity. Our patient had severe shortness of breath, change of voice in the form of hoarseness, and pain. A similar case was described by Dyste. His patient complained of similar symptoms, but less severe [5].

As a result of the damage of the laryngeal cartilages, the inhaled air enters into the subcutaneous tissue. This causes a rise of subcutaneous emphysema of the neck at first, then the face and chest. If the damage is greater, the air may enter the mediastinum and pleura, manifested by pneumothorax and mediastinal emphysema [6, 7].

The performance of classic X-ray of the chest allows for quick identification of the pneumothorax and mediastinal emphysema. If we expect other injuries, we should perform a CT of the neck and chest. For our patient, due to the fast increase of the symptoms, it was decided to urgently perform a CT of the neck and chest (Fig. 1). The finding of bilateral pneumothorax and mediastinal emphysema led us to suspect damage of the respiratory tracts and allowed us to make the final and correct diagnosis.

In cases in which we suspect laryngeal or tracheal damage, the gold standard is to perform bronchoscopy. Its efficacy is estimated at $86 \%$. In a study performed on 53 patients after chest and neck injury, 28 had damage within the respiratory tract [7]. In our patient, the conservative treatment failed. Despite using the drain, the subcutaneous emphysema was growing. The performance of bronchoscopy helped to identify the damage of the larynx and the performance of the recovery treatment.

The case of our patient shows how dynamic the course of the laryngeal damage can be. Cases found in the literature were characterized by lower dynamics of symptoms and usually did not require surgical treatment.

The case shows that: blunt neck injuries may be lifethreatening, sport professions should have good medical coverage, appropriate treatment for each stage of evacuation and specialized treatment provide good treatment results.

\section{Disclosure}

Authors report no conflict of interest.

\section{References}

1. Delaney JS, Al-Kashmiri A. Neck injures penetrating to emergency departments in the United States from 1990 to 1999 for hockey, soccer and American Football. Br J Sports Med 2005; 39: 1-5.

2. Bechman SM. Laryngeal fracture in high school football player. J Athl Trai 1993; 28: $217-218$.

3. Hagr A, Kamal DR, Tabah R. Pharyngeal perforation caused by bunt trauma to the Neck. Can J Surg 2003; 46: 57-58.

4. Al-Kasmiri A, Delaney JS. Head and neck injures in football (soccer). J Trauma 2006; 8: 189-195.

5. Dyste KH, Newkirk KM. Pneumomediastinum in a high school football player: a case report. J Athl Trai 1998; 33: 362-364.

6. Back GW, Banfield G. Surgical emphysema and pneumomediastinum in child following minor blunt injury to the neck. Postgrad Med J 1999; 75: 548-550.

7. Hara KS, Prakash UB. Fiberoptic bronchoscopy in evaluation of acute chest and upper airway trauma. Chest 1989; 96: 627-630. 